member of a family to be affected. Recently, however, Jane Chatten and Mary L. Voorhess discovered neuroblastomas in three of four siblings. ${ }^{4}$ They then noted that the mother was pregnant and that during the sixth month of this pregnancy she was excreting large amounts of catecholamine in her urine. The child was delivered at term and five months later was found to have a mediastinal neuroblastoma. There were thus four siblings in the same family with neuroblastomas. One child had neuroblastoma in situ and aganglionosis of ileum and colon; the other three had overt neuroblastomas. Up to the time of this report there had been only four recorded instances of a second affected child in the same family. One of these cases was reported by J. Zimmermann, ${ }^{5}$ who suggested the tumour was inherited as an autosomal dominant. Since the majority of neuroblastomas occur sporadically, either the tumour must arise by mutation or a dominant gene of variable penetrance may be responsible. ${ }^{4}$ Both parents had café-au-lait spots on their skin, which have a known association with neurofibromatosis; and some patients with the latter condition have developed neuroblastomas. ${ }^{6}$ It is thus possible that a complex genetic pattern affecting the development of the neural crest is at fault in some of these inherited tumours.

The child with a neuroblastoma may be seen on account of an enlarging abdomen or because secondary tumours have made their appearance. There may be associated anorexia, vomiting, and loss of weight, but pain is not an early feature as a rule. The abdominal mass is usually firm, lobular, and of limited mobility. It tends to be situated more medially than a renal mass if the sympathetic chain is the site of origin. Early spread to the liver is common and it may enlarge so much that it obscures the primary mass.

Routine investigations should include an abdominal radiograph and a pyelogram. Calcified areas in the tumour may be clearly visible. If the tumour arises in a suprarenal gland a pyelogram will show downward and outward displacement of the kidney. If the growth has infiltrated the kidney, however, it may be difficult to distinguish the tumour from one of primarily renal origin. In some cases the ureter may be kinked by tumour and a hydronephrosis results. A complete skeletal survey should be done in all cases of suspected neuroblastoma, as bony metastases commonly occur and indicate a poor prognosis.

Many tumours are biologically active and produce catecholamines, when there will be a raised output of 3 methoxy-4 hydroxy mandelic acid (V.M.A.) in the urine. Dopamine, noradrenaline, and adrenaline may also be excreted in abnormally high amounts. The detection of these substances in increased amounts in the urine is not only of diagnostic value, since the levels tend to fall if the tumour is successfully removed and this finding can be used to assess the efficacy of chemotherapeutic measures.

When no widespread metastases have occurred radical excision of the tumour mass is the best form of treatment. It has also been suggested that in cases where complete removal is impossible a "major surgical insult" will improve the outlook. ${ }^{8}$ This approach is far from elegant, and not all surgeons would agree to a partial onslaught on an apparently inoperable tumour. ${ }^{9}$

There is considerable conflict of opinion regarding the efficacy of radiotherapy. It seldom permits the resection of a previously inoperable tumour. Though the tumour is undoubtedly radiosensitive the frequency of widespread metastases militates against successful radiotherapy. One of the most recent assessments of radiotherapy in neuroblastoma has been reported from the Babies Hospital, New York, by J. F. Lingley and colleagues. ${ }^{10}$ Of their 56 patients 21 (38\%) were alive and well three or more years after diagnosis. Fifty of these 56 patients received radiotherapy, two with ganglioneuroblastoma were treated by surgery alone, and the remaining four died shortly after surgery or admission. When the disease was localized to the site of origin ( 25 cases) 17 survived $(68 \%)$ and included the two patients treated by surgery alone. None was given chemotherapy. Thirty-onc patients had distant tumour spread and only four survived (13\%). All four had chemotherapy in addition to surgery and radiotherapy, and credit for survival was given to the cytotoxic drugs. The authors conclude that radiotherapy is of considerable value in patients in whom the tumour has not spread, and if total removal of the tumour is followed by radiotherapy the outlook is excellent.

Spontaneous regression is known to occur in neuroblastoma, and is largely confined to children under 2 years of age. The frequency of its occurrence has been variously estimated from $1 \%$ to $8 \% .^{811}$ Some neuroblastomas may regress as a result of necrosis, and others are thought to mature to ganglioneuroma over a period of years. ${ }^{12}$

It is clear that the biological behaviour of neuroblastoma is very variable. The chromosome pattern of this tumour is also unusual. Direct spreads made from the tumour at operation have shown the presence of double-minute chromatin bodies. ${ }^{13}$ The significance of the chromosome changes found in neuroblastoma is uncertain, but they bear certain similarities to those in other embryonic tumours occurring in children.

This very unusual group of tumours is of considerable importance in early life. Further studies should be directed to the determination of the true familial incidence of these neoplasms and to a more accurate evaluation, possibly through the medium of clinical trials, of the various forms of therapy in current use. Although some success has already been achieved with localized tumours the occurrence of widespread metastases to the skeleton has defied attempts at achieving a permanent cure in the majority of cases.

\section{Hiatus Hernia}

One of the more puzzling features of a sliding hiatus hernia is that though free gastro-oesophageal reflux may be shown by barium studies the patient may have no symptoms. Even those patients with symptoms may have periods of remission, although the herniation and presumably the tendency to gastro-oesophageal reflux are constantly present.

Recently a series of 1,011 patients with sliding hiatus hernia, oesophagitis, or oesophageal stricture have been reported on by E. D. Palmer from the United States, ${ }^{1}$ and it is interesting to compare the results with a previous serics of 200 patients reported from Great Britain by V. Edmunds over 10 years ago. ${ }^{2}$ In the present series patients were investigated by barium studies, endoscopy, and oesophageal biopsy. About half of those with demonstrable hiatus hernia or oesophagitis had no related symptoms. Only a minority $(8.9 \%)$ complained of retrosternal burning pain, which was related to posture or associated with the reflux of fluid in the mouth. Most clinicians would hesitate to accept a sliding hiatus hernia as the cause of other symptoms, and certainly most surgeons would be reluctant to undertake operation in the absence of these symptoms. 
Severe haemorrhage occurred in $26.6 \%$ of the present series and required on average over 31 . of blood for replacement. This is wholly unlike the experience in Britain. In the series previously reported by Edmunds ${ }^{2}$ bleeding occurred in $15 \%$ and was nearly always minimal or occult. Recent measurements of occult loss of blood in 26 patients with hiatus hernia have shown that there was a mean loss of 15 ml. per day in anaemic patients and a mean loss of $3 \mathrm{ml}$. per day in those without anaemia. ${ }^{3}$ In Palmer's series a frequent association of both gall stones and diverticular disease with hiatus hernia was found $(10.2 \%$ ). It was rare for only two of these lesions to be present without the third. Hence the author believes it to be more than a chance association and favours the eponym "Saint's triad" for it.

The differentiation of oesophageal and cardiac pain is sometimes difficult, especially in those patients in whom both hiatus hernia and coronary artery disease are present, for the site of the pain and its radiation may be identical. The majority of those patients with reflux will use an adjective suggesting heat to describe their pain, whereas those with cardiac pain will usually describe constriction. However, in a minority it may be virtually impossible to decide from the history. Eome help may be gained from infusing N/10 hydrochloric acid into the oesophagus, for this will reproduce pain due to gastro-oesophageal reflux, ${ }^{4}$ but it may also cause reflex myocardial ischaemia. ${ }^{5}$

There is wide agreement that reduction of weight is a most effective means of controlling heartburn, and patients soon learn to avoid tight clothing, stooping, and lying flat in bed. Antacids and frequent small meals to avoid overdistending the stomach usually produce some symptomatic relief, but Palmer found them to be ineffective. ${ }^{1}$ Indeed, he believes that reflux of gastric contents is not responsible for the oesophagitis-an unorthodox view not shared by most authors, ${ }^{6-8}$ but he offers no clear alternative explanation. Squamous epithelium has little natural powers of resistance to withstand erosion by acid and pepsin. Once reflux of gastric contents occurs, ulceration may rapidly follow, and it will as rapidly heal once contact with gastric juice ceases. A similar sequence of events may be observed in the squamous epithelium of the skin surrounding a gastric fistula. The peptic ulceration usually consists of irregular ulcers which do not penetrate the muscularis mucosae ; but occasionally deep penetrating ulcers are found, usually in relationship to areas of columnar mucosa. These ulcers are likely to develop serious complications-for example, haemorrhage or perforation. ${ }^{7}$ The columnar mucosal lining is probably an acquired lesion. ${ }^{10}$

Only 3.9\% of Palmer's series of patients underwent surgical treatment, and the most frequent indication was serious haemorrhage. Again, experience in Britain is considerably

1 Palmer, E. D., Amer. f. Med., 1968, 44, 566.

- Edmunds, V., Quart. f. Med., 1957, 26, 445.

- Holt, J. M., Mayet, F. G. H., Warner, G. T., Callender, S. T., and Gunning, A. J., Brit. med. F., 1968, 3, 22.

- Bennett, J. R., and Atkinson, M., Gut, 1966, 7, 105.

- Morris, J. C., Shelburne, P. F., and Orgain, E. S., f. Amer. med. Ass., 1963, 183, 788.

- Allison, P. R., Surg. Gynec. Obstet., 1951, 92, 419.

, Sandry, R. J., Gut, 1962, 3, 189.

- Aylwin, J. A., Thorax, 1953, 8, 38.

- Barrett, N. R., Brit. F. Surg., 1950, 38, 175.

10 Adler, R. H., Int. Abstr. Surg., 1963, 116, 1.

1 Collis, J. L., Amer. f. Surg., 1968, 115, 465.

12 Skinner, D. B., and Belsey, R. H. R., F. thorac. cardiovasc. Surg., 1967, 53, 33 .

13 Belsey, R., Proc. roy. soc. Med., 1966, 59, 32.
14 Tanner, N. C., and Westerholm, P., Amer. F. Surg., 1968, 115, 449. different: 23 out of $145(16 \%)$ patients with sliding hiatus hernia underwent operation for symptoms that were not controlled by medical measures. ${ }^{2}$ It is the experience of many surgeons that such patients are very grateful for the relief of heartburn which had plagued them for years. Perhaps more patients should be considered for surgery, for provided the symptoms are certainly attributable to the hiatus hernia over $80 \%$ are completely relieved or greatly improved by operation. ${ }^{11} 12$

Dysphagia as a result of peptic oesophageal stricture is difficult to treat. Palmer managed all his patients by repeated dilatation. Though a patient's nutrition may be maintained by repeated bougienage, the relief of dysphagia is often far from complete, and this is not altogether surprising when the degree of structural damage and fibrotic narrowing is observed in a resected specimen. Most surgeons in Britain have favoured surgical treatment for peptic strictures of the oesophagus, with either resection with colonic ${ }^{13}$ or jejunal interposition, a lower partial gastrectomy, ${ }^{14}$ or even a bypass operation with subcutaneous colon between the oesophagus and the stomach.

Probably many patients with sliding hiatus hernia are never even referred to hospital: their symptoms are easily controlled by diet and alkalis. Only a more troubled minority find their way there, and only a small number of these will ever require operative treatment.

\section{Adenovirus Cystitis}

Patients with symptoms of acute cystitis but without detectable bacterial infection are a difficult clinical problem. ${ }^{1}$ Occasionally organisms such as trichomonas, T-strain mycoplasmas, candida, or the T.R.I.C. agent can be isolated, but usually no infectious cause for the symptoms can be found. Viruses of one kind or another can cause disease in most tissues and organs of the body, but none has so far been shown to produce symptoms in the urinary tract. Recently, however, a report from Sendai, Japan, has provided convincing evidence that viruses can cause acute cystitis. $^{2}$ In the cases described the virus was adenovirus type 11 .

Adenoviruses are best known as respiratory pathogens, but they also cause eye infections and probably play a part in some cases of mesenteric adenitis, intussusception, and gastroenteritis. $^{3}$ They are often found in the intestinal and respiratory tracts of healthy people as well as in those of patients, but have only rarely been reported-perhaps because rarely sought-in the urine. The isolation of adenovirus 11 from the urine of children with haemorrhagic cystitis is therefore of great interest.

Brit. med. F., 1968, 2, 192

2 Numazaki, Y., et al., New Engl. f. Med., 1968, 278, 700.

$s$ Potter, C. W., in Modern Trends in Medical Virology, ed. R. B. Heath and A. P. Waterson, 1967, 1, 162.

- Gresser, I., and Katz, S. L., New Engl. F. Med., 1960, 263, 452.

- Weller, T. H., and Neva, F. A., Proc. Soc. exp. Biol. (N.Y.), 1962, 111 215.

- Utz, J. P., and Szwed, C. F., Proc. Soc. exp. Biol. (N.Y.), 1962, 110, 841 .

' Utz, J. P., Houk, V. N., and Alling, D. W., New Engl. F. Med., 1964, $270,1283$.

s Gutenkuns:, R. R., and Heggie, A. D., New Engl. f. Med., 1961, 264, 374. 